at the termination of the two urethras now admits of accurate coaptation by sutures, or the normal urethra may be mobilized (Beck method) to a sufficient extent to admit of its insertion into the caliber of the new urethra, where it is held by sutures and the external

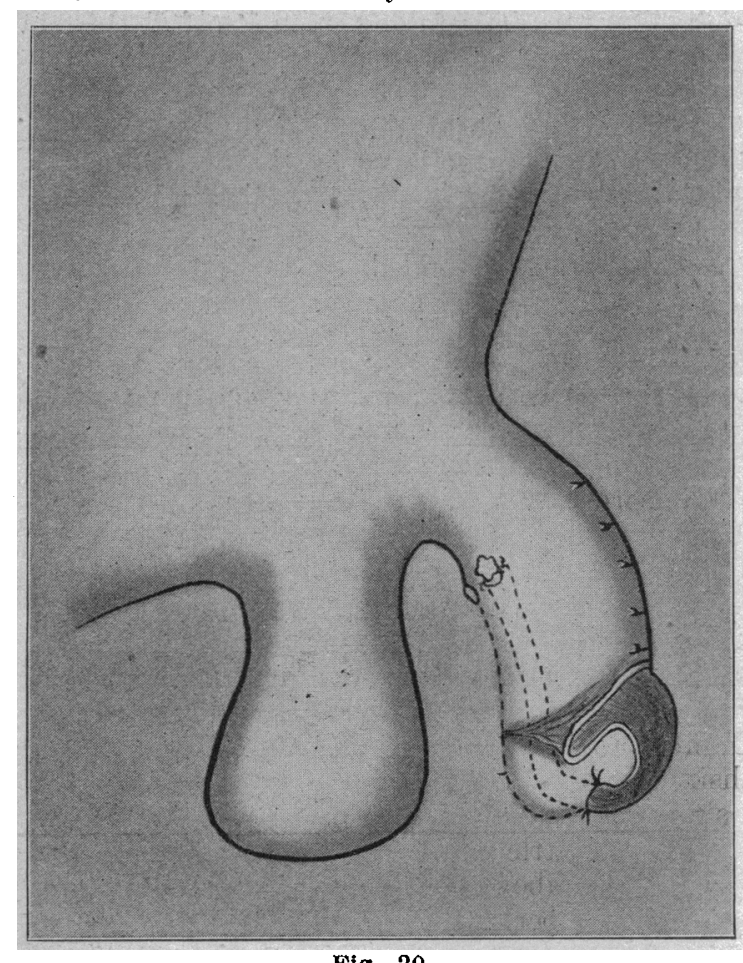

Fig. 20.

parts closed over this. (Fig. 21.) Occasionally a little urine escapes into the urethra and the entire canal is best drained by passing several silkworm strands of horsehair through the urethra and out alongside the catheter in the perineal opening. When union of the canals is complete the drains are removed and the perineal drainage will usually close itself in a few

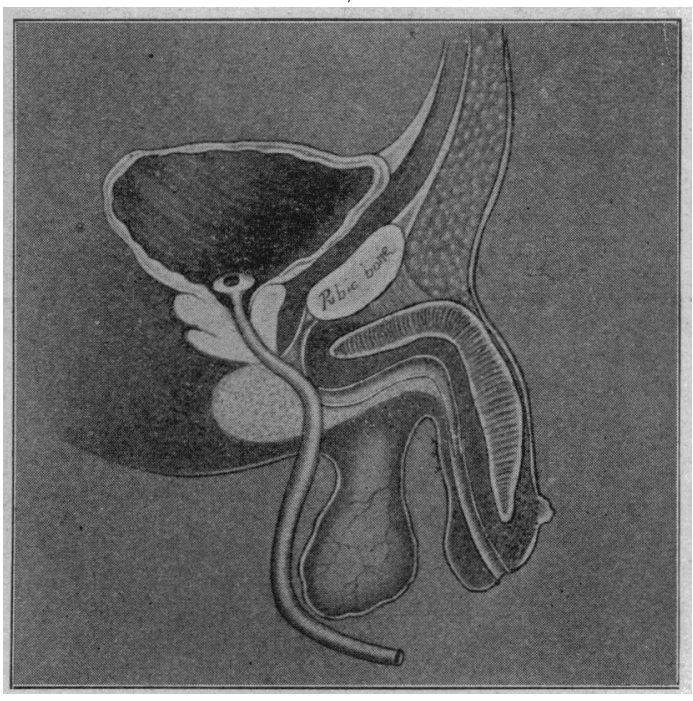

Fig. 21.

days. Horsehair and fine catgut have proved the best suture material for this form of plastic work.

The advantages of this combined operation are: 1, a urethral tube of thin elastic skin nearly approaching mucous membrane, yet having no hair surface to occasion later complications; 2 , a perineal drain for the bladder, with a self-retaining Jacobs' female catheter;
3 , a silkworm drain for the urethra; and 4, in being a method capable of application to the worst types of hypospadiac cases.

I report four cases of hypospadias cured by various methods :

CASE 1.--(St. Mary's Hospital Reports for 1897.) A boy of 4 years, penile type, was given two operations, the first a Duplay, with partial success; the second a Thiersch, with a good urethra.

CASE 2.- (St. Mary's Hospital Reports for 1898.) An adult, with the balanic type, was given two Thiersch operations, with a nearly perfect result.

CASE 3.-(St. Mary's Hospital Reports for 1900.) A boy 6 years of age, of the perineo-scrotal type with divided scrotum, at the first operation had two inches of urethra constructed from the prepuce and skin of the dorsum of the penis; at the second, bladder drainage, a Nelaton catheter in the perineum, but union at the juncture of the urethras failed. Urine passed by the catheter; bladder tenesmus. The third operation gave bladder drainage by means of Jacobs' self-retaining female catheter through the perineum, for eight days; silkworm strands in the urethra for drainage. Cure.

CASE 4.-(St. Mary's Hospital Reports for 1900.) A boy 8 years of age, the peno-scrotal type, was given two operations. The first was construction of $1 \% / 4$ inches of urethra of prepuce and skin from the dorsum of the penis; the second, bladder dramage, self-retaining Jacobs' female catheter through the perineum and union of the two urethras. Urethral drainage was by silkworm gut strands. Cure.

\section{THE POLLUTION OF STREAMS AND THE PURIFICATION OF PUBLIC WATER SUPPLIES.*}

COMPARATIVE EFFICIENCY OF SLOW SAND AND MECHANICAL FILTERS.

GEORGE M. KOBFR, M.D.

Professor of Hygiene, Medical School, Georgetown University. WASHINGTON, D. C.

COMPOSITION OF RIVER WATER.

River water is a mixture of spring, ground, rain and surface-water, but as the water-courses are the natural drainage channels of the country, it is not surprising that the wastes of human life and occupation should also find their way into the streams. It is for this reason that rivers, after passing through cultivated valleys with cities, towns, and villages or settlements on their banks, often contain a dangerous amount of mineral and organic matter. Rivers are always purer near their source; the amount of impurities increase as we descend the stream. Thus, for example, the Mississippi River at Minneapolis contains only 18.6 total solids per 100,000 , while the same river at $\mathrm{St}$. Louis contains 244.3 per 100,000 .

\section{RIVER POLLUTION.}

The sanitarian recognizes two principal forms of pollutinn, viz.: The amount of mineral matter, and, second, the character and amount of organic matter contained in the water. The amount of mineral matter depends largely upon the geological formation of the country and the erosive powers of the streams, but water containing 50 parts per 100,000 or 30 grains of solid matter per gallon is unfit for drinking purposes on account of its irritating effects upon the gastrointestinal tract. Beyond this, however, it is of no special significance, unless the water also contains metallic poisons or objectionable chemicals.

In regard to the Potomac River, which may serve as

* Presented to the Section on Hygiene and Sanitary Sclence, at the Fifty-first Annual Meeting of the American Medical Association, held at Atlantic City, N. J., June 5-8, 1900. 
a type of American rivers for our discussion, we know, for instance, that certain pulp mills, tanneries and manufacturing establishments discharge chemicals and various refuse; one paper mill alone discharges over 100,000 gallons of liquid into the river each day heavily laden with sulphuric and tannic acids.

These gross forms of pollution, although at times so great as to prove destructive to game fish, are of less interest to sanitarians than pollution with organic matter, especially sewage contamination derived from the towns and settlements within the Potomac drainage basin, which covers 11.043 square miles, with an estimated population of 491,813 people, or about 44.5 per square mile. ${ }^{1}$ Among the larger towns may be mentioned Cumberland, Frederick, Hagerstown, Harpers Ferry, Staunton, but as none of them are sewered, whatever contamination they produce is derived from surface drainage.

\section{CHEMICAL ANALYSES.}

Notwithstanding these numerous sources of pollution, the Potomac River, according to the chemical analyses, compares very favorably as regards purity wh other American rivers.

The following are the results tabulated for comparison by Colonel Miller and based upon 72 analyses of the Potomac water as delivered from the faucet in the laboratory of the health office, from July, 1897, to Jan. 31, 1900 , and daily analyses made by Mr. R. S. Weston, between July 1, 1899, and Jan. 20, 1900 :

\begin{tabular}{|c|c|c|c|c|c|c|c|}
\hline & 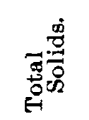 & 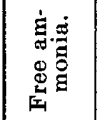 & 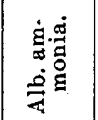 & 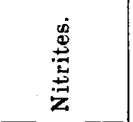 & 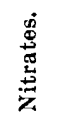 & 总 & 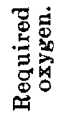 \\
\hline $\begin{array}{l}\text { Health office ... } \\
\text { Robert S. Weston, } \\
\text { Mason's safe limit. }\end{array}$ & $\begin{array}{l}126.7 \\
1390 \\
150-300\end{array}$ & $\left|\begin{array}{c}0.0008 \\
013 \\
.01-.12\end{array}\right|$ & $\mid \begin{array}{l}0.111 \\
.105 \\
.10-.28\end{array}$ & $\begin{array}{c}\text { Trace. } \\
0002 \\
.0135-.003\end{array}$ & $\begin{array}{l}0.639 \\
.73 \\
.42\end{array}$ & $\left|\begin{array}{ll}3 & 78 \\
2 & .60 \\
3 & 10\end{array}\right|$ & $\begin{array}{r}2.56 \\
450 \\
5-7 .\end{array}$ \\
\hline
\end{tabular}

BACTERIOLOGICAL ANALYSES

Now; let us inquire into the results of the bacteriological examinations of this water which have been made by various competent authorities at the Army Medical Museum, and by Kinyoun and Sprague, of the MarineHospital laboratory, during the past ten years. The latter also examined samples at or near all the important towns from the head waters of the Potomac and Shenandoah rivers, and may be said to accurately represent the bacteriological condition of the entire river. Intestinal organisms were found in over 90 per cent. of the samples. The number of bacteria varied from 150 to 20,000 per cubic centimeter, with an average of something over 1000 . The more recent examinations, conducted under the supervision of Colonel Miller from July, 1899, to March, 1900, show a minimum per cubic centimeter of 48 in July and a maximum of 51,000 for January, 1900, with an average of 3761 per cubic centimeter. Of the specimens taken on about two hundred different days, 50 per cent., or one-half, revealed the presence of the bacillus coli communis.

\section{TURBIDITY AND BACTERIA.}

This exhaustive study also confirmed the conclusions of Theobald Smith and others, that turbidity of the Potomac water is always accompanied by a larger amount of organic matter and germs, and that fecal bacteria and turbidity are coincident, simply because the same showers that bring along large sections of pulverized river banks also wash through the towns, barnyards, cesspools, and outhouses before finding their way into the creeks and river.

1. See Colonel Miller's report, Senate Doc. 259, p. 9.
SIGIFICANCE OF INTESTINAL BACTERIA.

The presence of intestinal bacteria is satisfactory evidence of pollution by fecal matter of man or animals and strongly point to the possibility of infection with typhoid bacilli.

Mr. Davis, of the Geological Survey, estimates that the sewage from the vicinity of Cumberland, a distance of about 134 miles, requires from two to four days to reach Washington aqueduct. We also know that typhoid bacilli retain their vitality for a number of days in ordinary water, and could therefore infect consumers of water in Washington.

TYPIIOID FEVER AND WATER-BORNE DISEASES.

My suspicions that typhoid fever germs may thus travel all the way from Cumberland were confirmed as early as the winter of 1889-90, by studying the effects of the typhoid fever epidemic at Cumberland upon the prevalence of the disease in Washington.

The records of the health office show that during this epidemic, from December, 1889, to April, 1890, the deaths from typhoid fever amounted to $\gamma 4$, as compared with 42 for the corresponding months of the previous year. Indeed, we had almost double the number of typhoid deaths during these months than for any similar period either before or since this epidemic.

Cumberland had about 45 deaths and 485 cases. Wahsington had 74 deaths and about 740 cases, and yet the starting-point of all was the excreta of one patient washed into a little run which empties into the Potomac about 300 feet above the pumping station of the watersupply for Cumberland. In the face of this fact and the almost constant presence of intestinal bacteria, I have no hesitation in declaring that the excessive typhoid fever rate of the national capital is largely due to contaminated Potomac water. We know the germs must be there, whether the bacteriologists find them or not, because the people who drank the water were taken sick, while the non-consumers remained exempt.

What has been said of the Potomac River is equally applicable to the Ohio, Mississippi, Merrimac, Connecticut, Missouri and other American rivers, because they are the sewers and at the same time the source of watersupply for nearly all the cities located upon their banks, and these cities, as shown by the statistics collected by the Marine-Hospital Service, show, moreover, a marked prevalence of typhoid fever, thus confirming what has been observed over and over again that this disease, as also cholera, dysentery and diarrheal diseases, can be carried from one town or city to another by means of a water-course. About three years ago Surgeon-General Wyman estimated, from statistics received in his office, that every year there are no fewer than 45,000 deaths caused by typhoid fever alone throughout the United States. This number has now reached, very likely, 50,000 , and, based upon an estimated mortality of 10 per cent., it is within reason to assume a yearly prevalence of 500,000 cases of this disease.

The average duration of a case is not less than thirty days. If we calculate that only $\$ 1$ per day is expended for care, treatment and loss of work and that the value of a human life is $\$ 5000$, we have a total loss in the United States every year of $\$ 400,000,000$ from one of the so-called preventable diseases. Reduce the prevalence of this single disease one-half, which has been accomplished in Europe and can be done here, and the question as to what public sanitation has accomplished will be answered from an economic point of view.

We would not think of establishing a vicious circle 


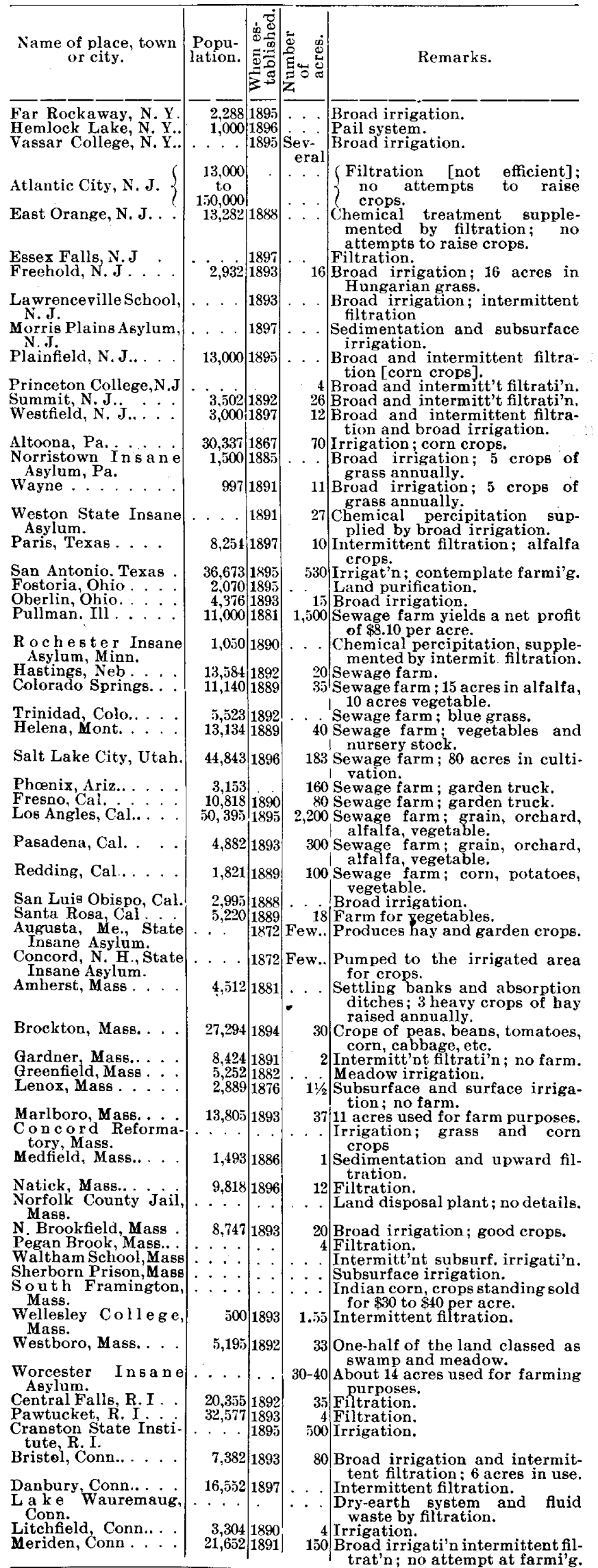

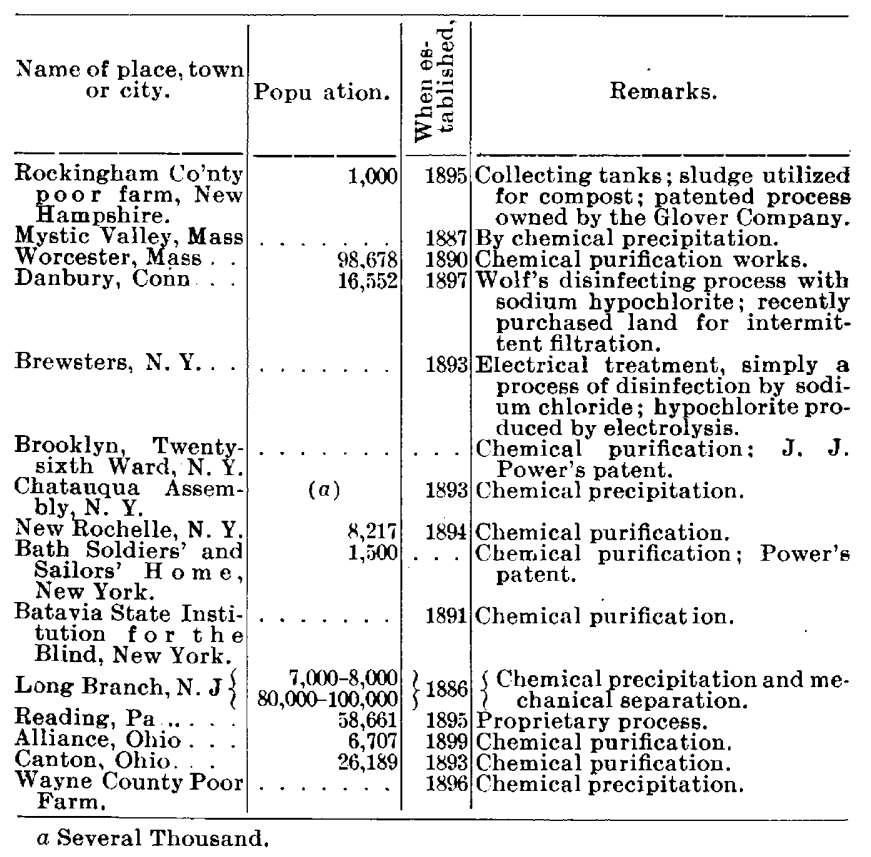

Table 3.- Showing the Average Number of Deaths from Typhoid Fever Per Annum isefore axd After Filtration. SaNd Filters.

\begin{tabular}{|c|c|c|c|c|c|}
\hline Name of town. & 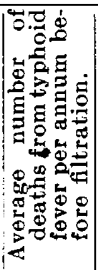 & 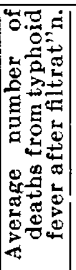 & 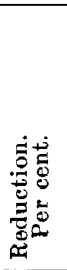 & 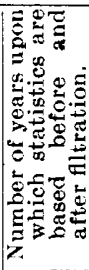 & Remarks. \\
\hline Lawrence, Mass & 52 & 13.8 & 73.5 & 5) & \multirow{5}{*}{$\begin{array}{l}\text { F i l t e r established } \\
\text { September, } 1893 \text {. } \\
\text { F i l t e r established } \\
\text { September, } 1895 \text {. } \\
\text { Filter established in } \\
\text { 1896. } \\
\text { Filter established in } \\
\text { 1894. }\end{array}$} \\
\hline Asbland, Wis... . & 39 & 4.5 & 88.5 & 2 & \\
\hline Hamilton, N. Y.. . & 0.66 & 0.33 & 50. & 3 & \\
\hline $\begin{array}{l}\text { Mount Vernon, } \\
\text { N. Y. }\end{array}$ & 3.4 & 1.8 & 47 & 5 & \\
\hline • & 95.06 & 20.43 & 78.5 & & \\
\hline
\end{tabular}

\section{Mechanical Filters.}

\begin{tabular}{|c|c|c|c|c|c|}
\hline Macon, Ga . & 10.5 & 7 & 33 & 4 & Filter established in \\
\hline Atlanta Ga. & 61 & 46 & 25 & 3 & Filter ostablished in \\
\hline Oakland, Cal. . & 19 & 17 & 11 & 5 & F i it e r established \\
\hline Reading, Mass . . & 4 & 1 & 7.5 & 1 & F il ter established \\
\hline Terre Haute, Ind. & 21.6 & 1i) & 31 & 5 & $\begin{array}{l}\mathrm{Filter} \text { established } \\
\text { (Natural filter). }\end{array}$ \\
\hline Elmira, N. Y... & 10 & 11 & $\mid \begin{array}{c}\text { Increase. } \\
10\end{array}$ & 1 & $\begin{array}{l}\text { July, } 1890 \text {. } \\
\text { F il te r established }\end{array}$ \\
\hline Newcastle, Pa. & 13 & 28 & 115 & 1 & $\begin{array}{l}\text { F i t t e r established } \\
\text { (New York), April, }\end{array}$ \\
\hline \multirow[t]{2}{*}{ Lexington, $\mathrm{Ky}$} & 18 & 64.2 & 256 & 4 & $\begin{array}{l}\text { F il t e r established } \\
\text { June. } 1895 .\end{array}$ \\
\hline & 157.1 & 189.2 & $\begin{array}{r}\text { Increase } \\
20.43 \%\end{array}$ & & \\
\hline
\end{tabular}

between our mouths and the drainage of our houses and stables and yet practically we have suffered this to be done upon the erroneous assumption that rivers purify themselves. While a certain degree of purification is possible by natural means, such as dilution with unpolluted water, deposition of suspended matter, the agency of aquatic animals and plants, the bacteria of nitrifica- 
tion, the destructive influence of sunlight upon microorganisms, and the chemical affinity of certain bodies, $I$ am glad that biologists have about come to the conclusion that "no river is long enough to purify itself."

What has been said of typhoid fever is equally true of other water-borne diseases like cholera, dysentery, cholera morbus, diarrheal diseases, and the transmission of the eggs of intestinal and other parasites, because the germs or eggs of these diseases are present in the intestinal tract and presumably also in sewage-contaminated water. Thus, for example, the cholera epidemic of Hamburg in August; 1892, resulting in 17,020 cases, with 8605 deaths, was caused by a band of gypsies camped on the banks of the river Elbe, and the discharges of one of its members suffering from cholera were emptied into the river, which at that time was served to the inhabitants of Hamburg without filtration. The epidemic spared the adjoining city of Altona, which derives its water from the same river after receiving the sewage of Hamburg with its 800,000 people, but Altona filtered its water and Hamburg did not.

\section{PREVENTION OF RIVER POLLUTION.}

When we remember that the general mortality of London a century ago was still 40 per 1000 , while at the present time it is between 20 and 21 per 1000 , and that no two factors have contributed so much to the prolongation of human life as the improvement of the air we breathe and the water we drink, it must be apparent that it is high time for civilized communities to take steps toward removing the danger to be found in rivers which are the sewers and at the same time the sources of public water-supplies. "One of the most pressing needs, therefore, is an investigation into the pollution of water supplies, which such pollution affects or threatens to affect the sanitary condition of the people of more than one State," because the individual states are powerless to protect themselves against the misdeeds of their neighbors.

Mr. Bartholett's bill for the appointment of a river pollution commission, first introduced five years ago, has not yet become a law. England enjoyed the benefit of such a commission as early as 1855 , and in order to prevent, remedy and remove the danger of polluted water-supplies adopted a comprehensive system for the disposal of sewage and of water filtration, the fruits of which are shown by a marked decrease in the number of cases of typhoid fever, diarrheal diseases, and consumption, amounting in some localities to over 50 per ont.

I maintain that no community or individual has a right to pollute streams used for public water-supplies any more than a man has to contaminate his neighbor's well. This principle is very well appreciated by some of the nations in Europe. Thus the inhabitants of a town in Belgium suffered from the effects of a river polluted by the French, and the French government not only compelled the offending city to dispose of its sewage by irrigation, but granted a subsidy for this purpose.

All that is needed in this country is a correct appreciation of the dangers, and the first step in this direction is the appointment of a commission. The Marine-Hospital Service, which has for a number of years satisfactorily performed the functions of a national board of health, could, with the aid of the hydrographers of the U. S. Geological Survey and special agents of the Department of Agriculture, perform this duty without any great expense to the Government.

\section{PURIFICATION OF SEWAGE BY IRRIGATION.}

Aftex determining the extent and dangers of river pollution, the remedy can be applied, and consists in the adoption of a system in which the sewage and noxious waste waters are utilized and disposed of by irrigation on so-called sewage farms, and the effluent and purified waters are returned to the streams.

This system has been in vogue in some European cities for many years. The city of Berlin purchased about 20,000 acres of land and, notwithstanding the enormous outlay of a little over $\$ 3,000,000$ for the land and over $\$ 10,000,000$ for the sewer system, operates these farms at a net profit of about $\$ 60,000$ per annum. The city employs men condemned to the workhouse as laborers at the farms, and practically converts vagabonds into producing classes, with a fair prospect, too, that many of these individuals will continue their honest efforts to become self-supporting citizens; moreover, the old manor houses of the individual farms are utilized as country homes for convalescents, and thus the beneficent effects of this system are felt in more than one direction.

It is a matter of great satisfaction, therefore, that within the past ten or twelve years over one hundred communities in the United States have established plants for the disposal of sewage. The first attempt in the establishment of a sewage farm in this country was made at the Augusta, Me., State Insane Asylum in 1872, since which time 78 plants for the disposal by irrigation and 15 by chemical treatment, etc., have been established, and over 40 more projected. I have prepared Table No 1 from data obtained in Mr. George W. Rafter's Brochure No. 22 of the U. S. Geological Survey, 1899, on Water Supply and Irrigation. Among the more prominent and successful sewage farms may be mentioned Brockton and South Framingham, Mass.; Bristol, Conn.; Plainfield, N. J.; Altoona and Wayne, Pa.; Pullman, Ill.; Hastings, Neb.; Colorado Springs, Colo.; Salt Lake City, Utah; Helena, Mont.; Phœnix, Ariz.; Fresno, Los Angeles, Pasadena, Redding, and Santa Rosa, Cal.

Heretofore it has not been considered necessary to prevent the pollution of rivers affected by tide waters. Dr. '(ann, of the Wesleyan University, in 1894, traced, however, an outbreak of typhoid fever to raw oysters which had been fattened in a place where they were liable to contamination by sewage from typhoid patients, and since then numerous instances have been reported elsewhere. It has been shown that typhoid fever germs remain viable in oysters from fourteen to thirty days, and the medical officer of the local government board of England, in the twenty-fourth annual report points out the danger of many of the oyster beds on the English coast from sewage pollution, all of which indicates that even this newly-discovered source of danger should be guarded against.

\section{PURIFICATION OF PUBLIC WATER SUPPLIES.}

The primary object of disposing of sewage by means of irrigation is the prevention of the so-called waterborne diseases. I do not believe, however, that this method alone can be relied upon, as instanced by the cholera epidemic at Hamburg and typhoid fever epidemics at Plymouth and Cumberland, where the dejecta of a single patient were sufficient to cause the mischief, hence prevention of river pollution should be supplemented by filtration of the water-supply on a large scale, of which there are two systems, the Americann or mechanical method, and the English or natural sand filtration. 
'Time will not permit me to enter into their respective merits except to say that the mechanical filters, as first pointed out by Mr. Hill, have accomplished very little in the reduction of typhoid-fever death-rates in cities where they are used. In the subjoined table five American cities using these mechanical devices are compared with five cities in Europe using water from sand filters, with an average for the year 1895 for the American cities of 46.8 typhoid deaths per 100,000 living, against 6 deaths per 100,000 for the foreign cities. That is to say, the American rate was almost eight times greater than the foreign rate.

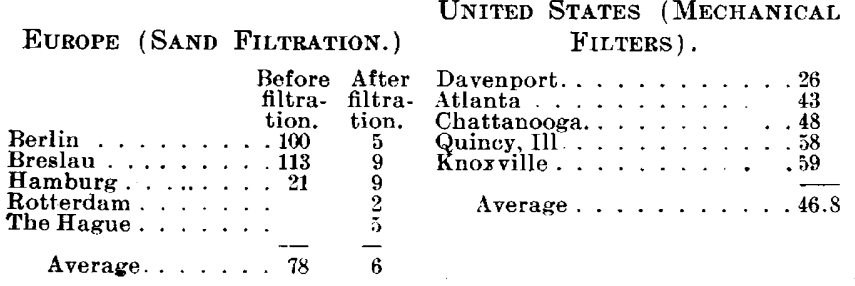

Lest this comparison between foreign and domestic cities be considered unfair, I have prepared Table No. 3, showing the average number of deaths from typhoid fever in several American cities before and after filtration. From this table we learn that while sand filters accomplished a reduction of 78.5 per cent. in the number of deaths from typhoid fever, the establishment and use of mechanical filters have coincided with an increase of 20.43 per cent. ; and even if we eliminate from our consideration Elmira, Lexington and New Castle, where an increase was noted, the reduction of typhoid fever in consequence of mechanical filtration amounts to only 26 per cent., as compared with 78.5 per cent. by the process of sand filtration.

\section{FLOATING KIDNEYS IN CHILDREN.* \\ I. A. ABT, M.D. CHICACO.}

Floating kidneys in children have not been frequently observed. Dr. Jules Comby, at the sixth annual meeting of the British Medical Association, in 1898, reported 18 cases, the children varying in age from one month to 10 years and over. It is remarkable to note that 16 of his cases occurred in girls. This proportion corresponds to the observations which have been made in adults. Ebstein states that 100 females to 15 males are affected, whereas Dietl believes that 100 adult females to one male are affected. Senator writes that he considers the last proportion to be the more nearly correct. Comby's cases do not, however, stand alone in the literature; quite a number of observers before him have reported these cases.

Steiner ${ }^{1}$ reported 1 case in a boy 9 years old, and also 2 cases in girls, respectively 6 and 10 years of age. In these 3 cases it was the right kidney which was involved.

Jacobi ${ }^{2}$ believes that cases of floating kidneys in infancy and childhood are for the most part congenital in origin. In children of 10 or 12 years he thinks the condition may be due to a fall or a jump. He has observed at least 8 cases in the course of thirty-six years.

W. R. Stewart ${ }^{3}$ reports the case of an infant of 8

* Read by title before the Section on Diseases of Children. at the Fifty-first Annual Meeting of the American Medical Association, held at Atlantic City, N. J., June 5-8, 1900.

1. Compendium of Diseases of Children, Prague, 1871.

2. Therapeutics of Infancy and Childhood.

3. Medical Record, Feb. 9, 1895. months, who had swallowed some pieces of plaster, and who suffered afterward from intestinal obstruction. After thirty-six hours of ineffectual medical treatment an operation was performed. A distinctly movable tumor could be felt on the right side, which was believed to be the obstructed gut. Upon opening the abdomen it was found to be a floating kidney, while an intussusception in the left hypogastric region explained the intestinal obstruction. The child had never suffered any inconvenience from the kidney, and its discovery was purely accidental. Richard Frey ${ }^{4}$ reports that in 500 autopsies he observed two eases of dislocated kidneys. In each case the kidney of the right side was the one involved. He found that the parenchymatous tissue, the vessels, and the ureters as well as the pelvis $\sigma_{i}$ the kidneys were normal. It is a fact well recognized that under normal conditions the kidneys have a certain mobility. In individuals with relaxed abdominal walls the lower pole may be frequently felt during deep inspiration. By floating kidney is meant an abnormal mobility of one or both kidneys, so that the entire organ can be palpated through the abdominal wall. (Senator.) ${ }^{5}$

The etiology of these cases in children, as in adults, is not altogether clear. In adults it is known that the influence of sex is a marked factor, the condition being much more common in women than in men, a fact to which reference has already been made. Not infrequently floating kidney is only one symptom of a general enteroptosis-described by Glenard. Traumatism undoubtedly acts as the direct exciting cause very often. Cases are recorded where blows, falls, the carrying of heavy weights, violent pressure and straining, whoopingcough and a variety of other causes of the same nature have been sufficient to loosen the kidney and cause an undue mobility.

Relaxation of the abdomen after pregnancies, abdominal tumors, ascites, rapid emaciation which leads to a partial or complete disappearance of fat within the renal fascia, may lead to the condition in adults. We must also consider that conditions which influence the weight of the kidney will be sufficient cause to eventually drag the kidney from its normal position and give rise to abnormal mobility. We have, for example, tumors of the kidney, and hydronephrosis.

The recent contributions of Wolkow and Delitzen, ${ }^{6}$ on this subject, contain some interesting facts, obtained from experiments on the cadaver. The authors show that the kidneys are attached to the posterior wall in the paravertebral spaces (nischen). These spaces, under normal conditions, are of some depth, and are funnelshaped below. In the cases where one or both kidneys had moved from their normal position, it was observed that these spaces were cylindrical, and the depth was less marked. The intra-abdominal pressure is an important factor in the fixation of the kidney. The authors also show that the anterior abdominal wall is an important factor in supporting these organs. They believe that the abdominal wall serves as a bandage, and the intestines as an elastic pad, both structures thus serving to support the kidneys.

In very young infants we are compelled to accept the congenital origin of floating kidney. In older children there can be doubt that a congenital predisposition for the disease existed. The hypothesis of Wolkow and Delitgen already cited may be invoked to explain this congenital tendency. The exciting cause may consist

4. Inaug. Diss., Zurich, 1886.

5. Ziemssen Speclelle Pathologie der Therapie, vol. xix.

f. Abstract in Centralbl. f. Chir., 1898. 